$$
\begin{array}{cc}
\operatorname{coN} F-8405 / 93- & 28 \\
\text { REPORT ON SOLAR NEUTRINO EXPERIMENTS } & \text { DIIL- }-34995 \\
\text { DEE } 84014567
\end{array}
$$

R. Davis Jr., B. T. Cleveland and J. Ko Rowley

Brookhaven National Laboratory, Upton, NY 11973

ABSTRACT

A summary is given of the status of solar neutrino research that includes results of the Brookhaven chlorine detector, a discussion of the development of the gallium, bronine, and lithium radiochemical detectors, and some proposals for direct counting detectors. The gallium and bromine radiochemical datectors are developed and are capable of giving critical information of interest about neutrino physics and the fusion reactions in the interior of the sun. A plan for building these detectors is outlined and a rough cost estimate is given. A review is given of the plans in the Soviet Union in solar neutrino research.

\title{
THE FUSION REACTIONS IN THE SUN
}

The sun's energy is generally believed to be a set of hydrogen fusion reactions that convert hydrogen into helium with the emission of positrons, gammas and neutrinos. The goal of solar neucrino research is to observe the neutrino spectrum from the sun in order to test this theory quantitatively, and thus provide essential information needed to understand the interior of the sun and the evolution of stars. In addition this research is of importance to the understanding of nuclear fusion processes and the physics of neutrinos.

The standard theory of the sun and the predicted solar neutzino spectrum was covered in $W$. Haxton's report to this conference and is described in earlier articles.1, 2 For the purposes of the discussion here it is convenient to summarize the solar neutrino spectrum in the form of the three branches of the proton-proton chain (PPI, PPII and PPIII) and the small contribution ( $2 \%$ ) from the $C-N$ cycle. These cycles are shown in Table I along with the neutrino fluxes calculated from the standard solar model.2

\section{RESULTS OF THR CHLORINE EXPERIMENT}

A solar neutring detector based upon the neutrino capture reaction ${ }^{37} \mathrm{Cl}\left(\nu, e^{-}\right){ }^{37}$ Ar was built in the period 1965-1967 and designed to observe the anticipated flux of neutrinos from the sun. The results of this experiment are well known. The measurements show that the capture rate $1 n{ }^{37} \mathrm{Cl}$ is below that predicted by the standard solar model calculations. This experiment has been in operation continuously and during this time improvements have been made in counting techniques and analysis. There has been a reduction in counter background that has greatly improved our detection sensitivity and characterization of ${ }^{37} \mathrm{Ar}$ decay events. A maximum likelihood method of statistical analysis 
Table I The preton-proton and carbon-nitrogen cycles

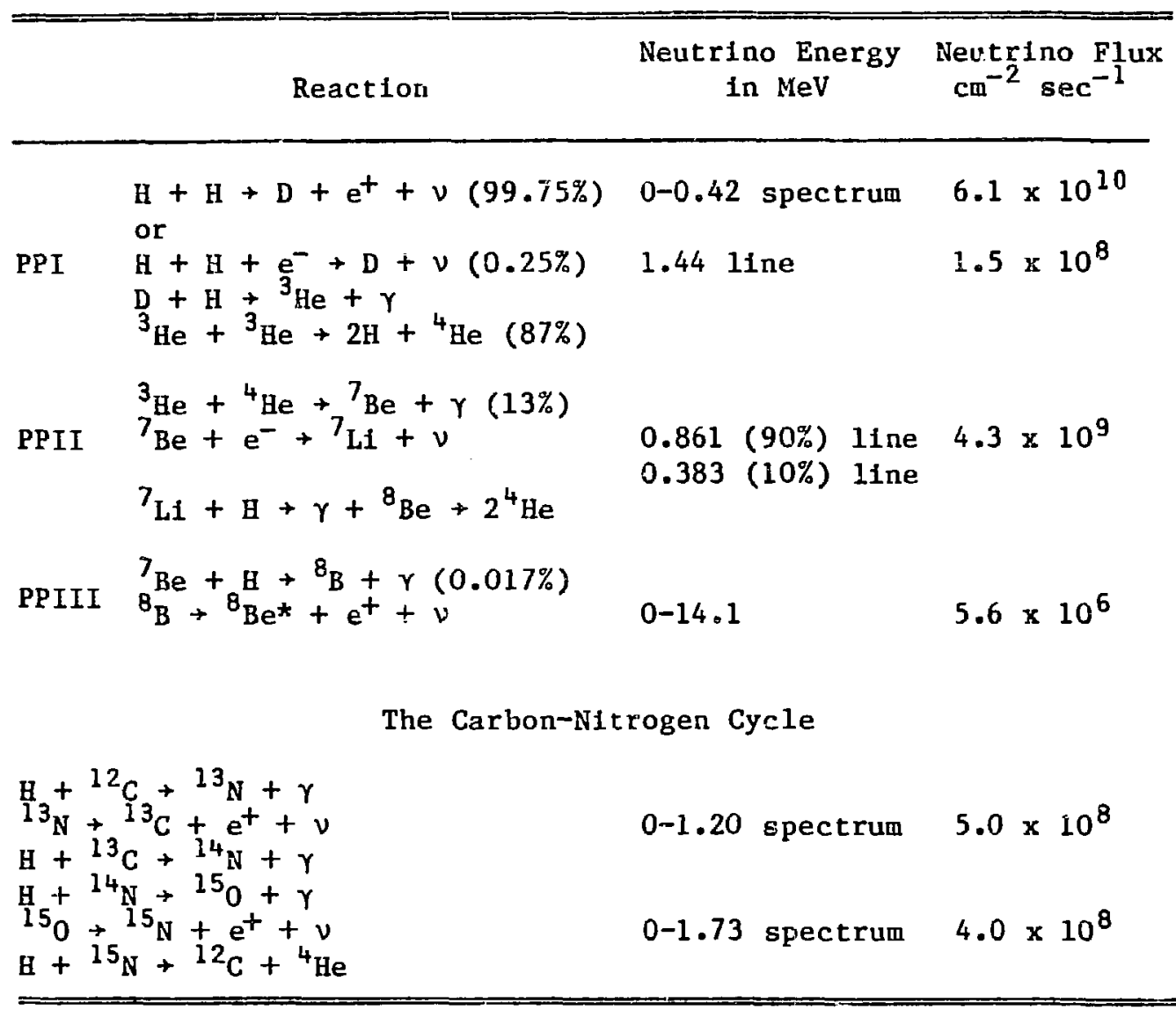

was developed to analyze the time distribution of the recorded events. The combined result of 59 observations performed during the period 1970-1983 is shown in Figure Also shown are the yearly average values. The results may be summarized as follows:

(1) The combined ${ }^{37} \mathrm{Ar}$ production rate over this period is $0.47 \pm 0.04{ }^{37} \mathrm{Ar}$ atoms per day in 615 tons of $\mathrm{C}_{2} \mathrm{Cl}_{4}$. Allowing for a background ${ }^{37} \mathrm{Ar}$ production from cosilic ray muons and neutrinos of $0.08{ }^{37} \mathrm{Ar}$ per day, 4 the neutrino capture rate that may be ascribed to solar neutrinos is $2.1 \pm 0.3$ SNU (SNU = Solar Neutrino Unit $=10^{-36}$ captures $/ \mathrm{sec}{ }^{37} \mathrm{Cl}$ atom).

(2) There is an indication that the yearly average ${ }^{37} \mathrm{Ar}$ production rate is anti-correlated with the solar activity cycle. The two highest experimental runs correlate in time with large solar flares and high energy proton fluxes ( $>150 \mathrm{MeV}$ ) observed in the eerth's atmosphere. 5

The neutrino capture rate expected in ${ }^{37} \mathrm{Cl}$ derived from the standard solar model is in the range 6-8 SNU depending on the values chosen from the measured data and the opacity values that are used.6. Considerable effort in recent years has been devoted to remeasuring the nuclear reaction cross sections that lead to the production of ${ }^{8} \mathrm{~B}$ in the sun, $7,8{ }^{3} \mathrm{He}(\alpha, \gamma){ }_{\mathrm{Be}}$ and 
${ }^{\prime} B e(P, Y)^{8} \mathrm{~B}$. There are many so-called non-standard solar models that predict neutrino capture rates in the range 1.5-2.5 SNU. These models are directed at reducing the internal temperatures in the sun by introducing continuous mixing, diffusion processes, Low heavy element abundances, a helium core, a fast rotating core and internal magnetic fields. All of these models have features that either conflict with other observations or disagree with our present understanding of the physics of stellar structures. 9 It is important to recognize that the chlorine experiment is predominantly sensitive to the flux of ${ }^{8} B$ neutrinos (PPIII branch) and the flux of these neutrinos is extremely sensitive to the internal temperatures in the sun.

Another explanation that has been advanced for the low solar neutrino capture rate in ${ }^{37} \mathrm{Cl}$ is that the electron neutrinos produced in the sun change to neutrinos of the muon, tauon, etc., flavors in the 8 minutes it takes them to traverse the sun and reach the earth. 10,11 According to the usual analysis of neutrino vacuum oscillations, the oscillation length depends upon
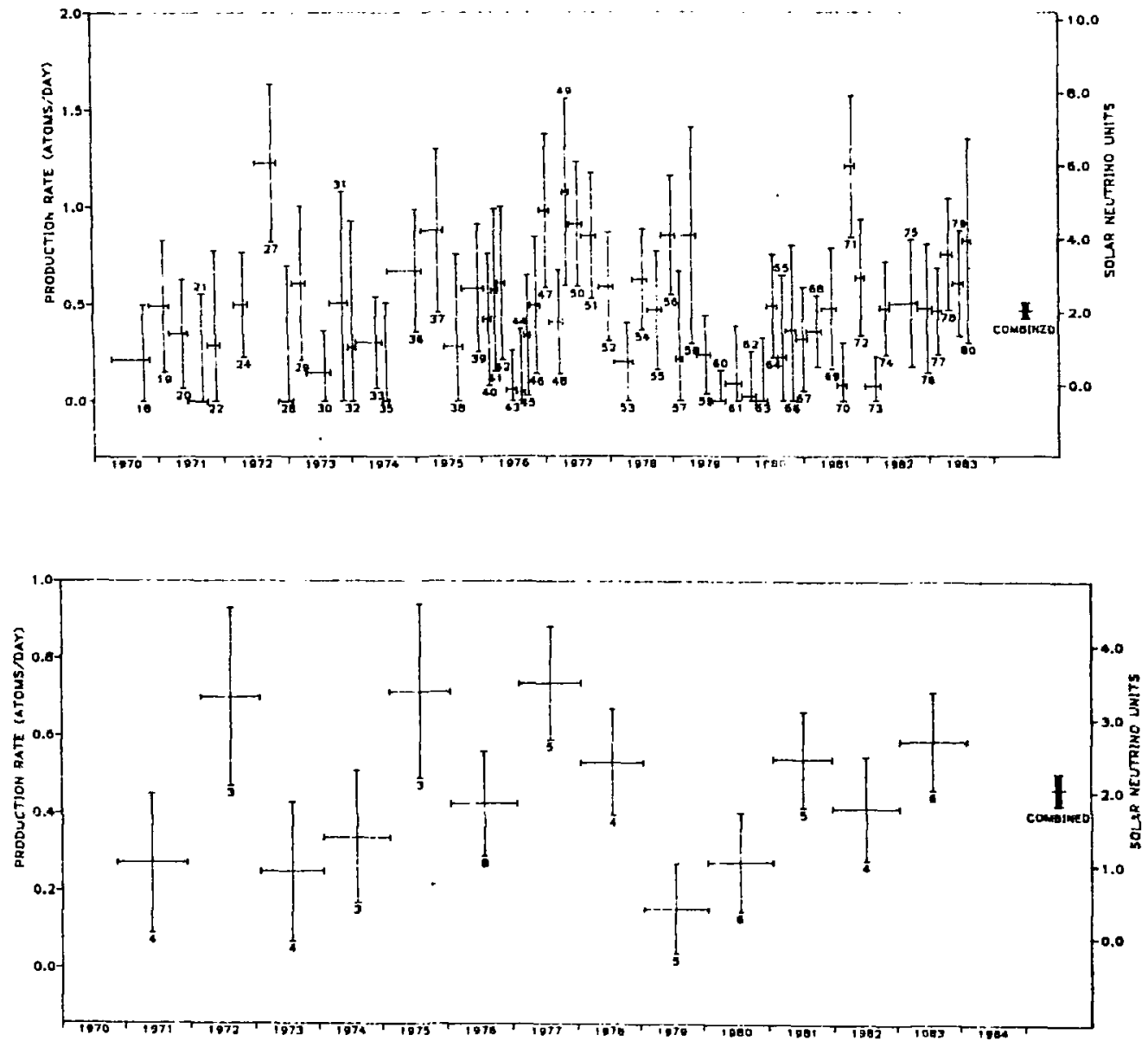

Fig. 1. Experimental results from the chlorine solar neutrino experiment: upper--individual measurements; lower-yearly averages. 
the difference in the squared wasses between the neutrinos $\left(\delta \mathrm{m}^{2}\right)$ and the mixing angle. There is little theoretical guidance for the magnitude of these parameters. Numerous experiments have been carried out at reactors and accelerators to search for the phenomena of neutrino oscillations and at the present time there is no clear evidence for neutrino oscillations at distances as great as the earth's radius. A solar neutrino detector capable of observing the low energy neutrinos from the $\mathrm{H}-\mathrm{H}$ reaction (PPI branch) is the best and perhaps the only way of testing for neutrino oscillations at $\delta \mathrm{m}^{2}$ as small as $10^{-8}(\mathrm{eV})^{2} .12$

NEW SOLAR NEUTRINO EXPERIMENTS

It has been known since 1968 that the solar neutrino capture rate in ${ }^{37} \mathrm{Cl}$ was below theoretical expectation. A considerable effort has been devoted toward developing racilochemical detectors based upon using gallium, bromine and lithium as target elements. In addition a number of detectors based upon observing the neutrino capture or scattering event directly have been suggested. However, at the present time there are no plans in the United States for bullding a second experiment. A direct experinental proof that the sun is producing energy by hydrogen fusion is a problem of great fundamental interest. The cost of carrying out the next generation solar neutrino experiment is indeed very modest on the scale of the experiments and facilities discussed at this conference.

Table II summarizes the experiments that have been suggested and their relative sensitivity to the three branches of the proton-proton cycle, and the corresponding neutrino source in the sun.

Table II Summary of solar neutrino detectors

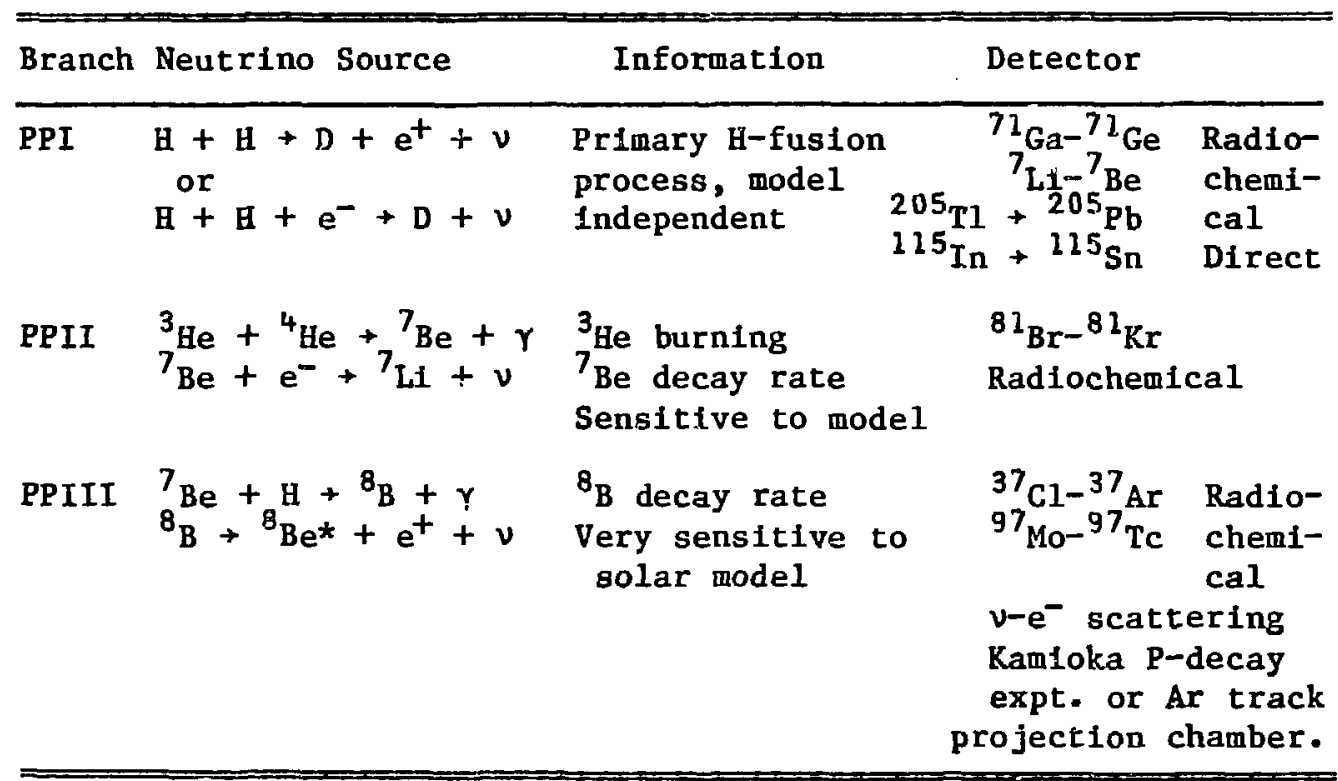


The proton-proton chain is initiated with the $\mathrm{H}-\mathrm{H}$ reaction, and the integrated rate of this reaction is essentially

independent of the details of the solar model. Because of this presumed fact, astrophysicists have placed great confidence in the predicted rate of the $\mathrm{H}-\mathrm{H}$ reaction in the sun (expected error around 3\%). An experiment capable of observing the low energy neutrinos from this reaction would constitute a critical test of the theory. If a low rate for this reaction is observed, the most likely explanation would be that the electron neutrino oscillates, decays, or in some way is lost. In the context of the oscillation hypothesis an accurate experimental observation of this fluy could give limits on values for the mixing angle and $\delta \mathrm{m}^{2}$ not achievable by any other experiment.

Because of these -oncepts there has been an emphasis since 1978 to develop a neutrino detector capable or observing these low energy neutrinos.13. The 115 In experiment based upon tine reaction $v+{ }^{15} \mathrm{In}+\mathrm{e}^{-}+{ }^{115} \mathrm{Sn} *+{ }^{115} \mathrm{Sn}+2 \gamma$ has the capability of observing the neutrino spectrum by detecting the emitted electron in colncidence with two successive low energy gammas. A neutrino detector based upon this principle that is capable of observing the solar flux is technically extremely difficult. Work on this approach will be reported at this conference by Martin Deutsch. ${ }^{14}$ The ${ }^{205} \mathrm{Tl}$ experimental technique suggested by $M$. Freedman, 15 involves obtalning a well shlelded geological deposit containing a thallium mineral since the product ${ }^{205} \mathrm{~Pb}$ has a half life of $1.5 \times 10^{7} y$ ars. There is a deposit of the mineral Lorandite in Yugoslavia that appears to be satisfactory. However, work on the thallium radlochemical detector has been temporarily abandoned because of the lack of support. The major effort has been devoted to the gallium radiochemical system for observing the low energy neutrinos from the $\mathrm{H}-\mathrm{H}$ reaction. The potentlal of this experiment will be discussed at the end of this report. The 11thlum experiment can observe the electron capture branch of the primary $\mathrm{H}-\mathrm{H}$ reactior. This so-called PeP reaction occurs at a rate 380 times lower than the $\mathrm{H}-\mathrm{H}$ reaction and the rate can be reliably calculated. Even with this very unfavorable factor the solar neutrino capture rate in ${ }^{7} \mathrm{Li}$ is relatively high and only a modest quantity of lithlum is required. The main difficulty with the lithlum experiment is the measurement of the product ${ }^{7} \mathrm{Be}$.

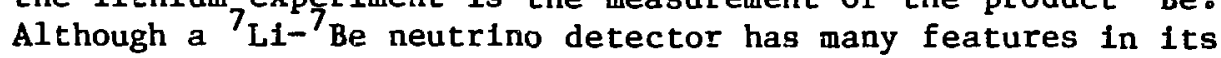
favor work on this technique in this country was abandoned in 1978.16

The ${ }^{7}$ Be decay neutrinos From the PPII branch have the second highest flux predicted by solar model calculations. A measurement of this flux would determine the rate of ${ }^{3} \mathrm{He}$ burning by the ${ }^{3} \mathrm{He}(\alpha, \gamma){ }^{7} \mathrm{Be}$ reaction. Information on this rate would be of great value in understanding the solar model and the chlorine experlmental results, and would be needed to interpret the results of a gallium expt iment.1 By virtue of the unique sensitivity of the three radiochemical detectors, gallium, bromine, and chlorine for the characteristic neutrino sources in the sun, one can in principle determine the solar neutrino spectrum by 
combining the rates observed by these three detectors. The status of the development of the bromine detector will be given later in this report.

It is of great interest to check the resulcs of the chlorine experiment to assure that the low signal obsf cred is indeed attributable to the decay of ${ }^{8} \mathrm{~B}$ in the sun. One can prove that the neutrinos come from the sun by observing the event directly and correlating the direction of the emitted electron or scattered electron with the sun's location. The ${ }_{B}^{8}$ neutrinos are the only solar neutrinos with sufficient energy to obtain even a rough angular correlation. In the past a number of ${ }^{8} B$ neutrino detectors were suggested and development work was carried out. In recent years Herbert Chen has developed a liquid argon time projection chamber that could be applied to coserving ${ }_{B}$ neutrinos.17 The technique has the resolution, but one cannot foresee at the present time whether a full scale detector is feasible and would have a sufficiently low background counting zate. The possibility of applying the Kamioka proton-decay detector to observe ${ }_{B}$ decay neutrinos will be aiscussed in Alfred Mann's report at this conference.18

\section{THE GALLIUM AND BROMINE EXPERIMENTS}

The radiochemical method of observing solar neutrinos has the advantage of high sensitivity, low energy threshold and low cost. In the foreseeable future it appears unlikely that the direct counting method for determining the solar neutrino energy spectrum and neutrino direction will be able to determine the critical neutrino fluxes from the $\mathrm{H}-\mathrm{H}$ reaction, the $\mathrm{PeP}$ reaction and ${ }^{7} \mathrm{Be}$ decay in the sun. The development of gallium and bromine radiocherical detectors is essentially complete, and full scale detectors could be built. Because of the fact that the radiochemical method is not capable of observing a single neutrino source, it is necessary to have the individual rates from ${ }^{37} \mathrm{Cl}$, ${ }^{8} 1_{\mathrm{Br}}$ and ${ }^{7} \mathrm{Ga}$ to determine the solar neutrino energy spectrum. In addition there is the question of the contribution from excited states in ${ }^{1} \mathrm{Ge}$ and $81_{\mathrm{Kr}}$, a question that will be resolved by $\mathrm{p}, \mathrm{n}$ reaction studies. 1,19

For each of these detectors, Table III gives the percent of the total solar neutrino capture rate that would be anticipated from each neutrino source in the sun. The solar model selected for this table gives a total neutrino capture rate $1 \mathrm{n}{ }^{37} \mathrm{Cl}$ of 1.9 SNU, consistent with our observations. This model was chosen as the best estimate of the solar neutrino fluxes to use for planning new experiments. The dominant source is indicatea by [] around the percentage value for each of the four detectors. We would like now to summarize the present status of the gallium and bromine radiochemical detectors.

Gallium. The gallium method was developed in a collaborative effort by Brookhaven National Laboratory, the Max-Planck-Institute fnr Nuclear Physics (Heidelberg), the Welzmann Institute, and the Institute for Advanced Study. The neutrino capture reaction 
Table III Comparison of radiochemical solar neutrino detectors. The percent of the capture rate from various solar neutrino sources is given for a solar model with a rate of 1.9 SNU in ${ }^{37} \mathrm{Cl}$

\begin{tabular}{|c|c|c|c|c|}
\hline Neutrino source & ${ }^{\mathrm{Ga}}{ }_{\mathrm{Ga}}{ }^{\mathrm{7}}{ }^{1}{ }^{\mathrm{Ge}} \mathrm{Ge}$ & $8 i_{\mathrm{Br}-{ }^{8} 1_{\mathrm{Kr}}}^{\text {Bromine }}$ & $\begin{array}{l}\text { Lithium } \\
7 \mathrm{Li}-7_{\mathrm{Be}}\end{array}$ & $\begin{array}{l}\text { Chlorine } \\
37 \mathrm{Cl}-{ }^{37} \mathrm{Ar}\end{array}$ \\
\hline $\begin{array}{l}p+p \rightarrow d+e^{t}+v \\
p+p+e^{-}+d+v \\
7 \text { Be decay } \\
8 B_{B} \text { decay } \\
13_{N} \text { decay } \\
15_{0} \text { decay }\end{array}$ & $\begin{array}{l}{[81]} \\
2.7 \\
14 \\
0.3 \\
1.0 \\
1.4\end{array}$ & $\begin{array}{c}0 \\
17 \\
{[64]} \\
6.2 \\
4.6 \\
4.6\end{array}$ & $\begin{array}{c}0 \\
{[51]} \\
8.9 \\
20 \\
3.5 \\
16\end{array}$ & $\begin{array}{c}0 \\
12 \\
23 \\
{[59]} \\
1.4 \\
4.4\end{array}$ \\
\hline Total rate in SNU & 88 & 6.8 & 19 & 1.9 \\
\hline $\begin{array}{l}\text { Tons of element } \\
\text { needed for } 1 \text { neutrino } \\
\text { capture per day }\end{array}$ & 39 & 460 & 7.6 & 1460 \\
\hline
\end{tabular}

$v+{ }^{71} \mathrm{Ga}+{ }^{71} \mathrm{Ge}+\mathrm{e}^{-}$has a threshold of $232.2 \mathrm{keV}$ and the half life of $7 i_{\mathrm{Ge}}$ is 11.4 days. The target material used is a hydrochloric acid solution of gallium chloride. Germanium is easily removed from this solution by purging with gas, the germanium being released as the volatile compound, $\mathrm{GeCl}_{4}$. The germantum tetrachloride is easily removed from the gas stream by a simple water scrubber column. The germanium recovered is then converted to germane, $\mathrm{GeH}_{4}$, a gas that can be introduced Into a small gas proportional counter. A pllot experimental system contalning 1.3 tons of gallium (11quid volume $3 \mathrm{~m}^{3}$ ) was built to test the procedures on an englneering scale. We found that germantum could be recovered, and placed in the counter as germane with a $95 \%$ yield in a period of 16 hours. 20 With this $1.3-$ ton facility the cosmic ray gackground production of $71_{\mathrm{Ge}}{ }^{68} \mathrm{Ge}$, and ${ }^{69} \mathrm{Ge}$ was measured and the yield of ${ }^{91} \mathrm{Ge}$ produced by fast neutrons was determined. A 15-ton detector could be bullt by scaling this system up by a factor of 12. This quantity of liquid coulc be contalned in thirteen 750-gallon alass-1ined tanks. Tanks of this design, chosen because of the corrosive nature of the acid gallium chloride solution, are comercially avallable and of sultable size to be carried underground by a mine holst.

A valuable feature of the gallium sular neutrino detector is that it is possible to show that the signal observed is indeed from neucrinos and not from background reactions. The major background effect underground arises from cosmic ray muon intiractions. Measurement with gallium chloride targets in the Fermilab muon beam show that the production of $69 \mathrm{Ge}$ (39 hour half-life) is four times greater than that for $71_{\mathrm{Ge}} 21$ one can thus easily search for ${ }^{69} \mathrm{Ge}$ in a full scale solar neutrins experiment to test whether the ${ }^{7} \mathrm{Ge}$ signal observed is from muors 
or neutrinos. the neutrino reaction producing ${ }^{69} \mathrm{Ge}$ has a higher threshold (2.23 MeV) and a lower cross section, 22 so ${ }^{69} \mathrm{Ge}$ would not be produced by solar neutrinos. Another background effect arises from internal natural alpha emitters. Our experience shows that the ${ }^{71} \mathrm{Ge}$ production from alphas emitters is very low in commercially avallable gallium chloride solutions. Nevertheless, this background effect can be monitored in these chlorinecontaining solutions by observing the production of ${ }^{37} \mathrm{Ar}$.

The gallium collaboration requesced funds to build a gallium solar neutrino detector using 45 tons of gallium during the period 1981-1983 without success. Included in the plans was a calibration. test using 2-3 megacuries of ${ }^{51} \mathrm{Cr}$ as a neutrino source. Tes Irradlations were performed in the HFIR reactor at Oak Ridge, and it was concluded that only 0.95 megacuries could be prepared. A source of this intensity would require 12 tons of gallium in solution form to make the measurement and would require a 2-3 year effort.

With this experience behind us we now propose carrying out a solar neutrino measurement using 15 tons of gallium. Since it is most important to determine the solar neutrino flux, we recommend that all effort be directed to this problem and the source experiment be deferred. A Monte Carlo analysis has been made of the statistical error that would be achieved. The results of our analysis are presented below.

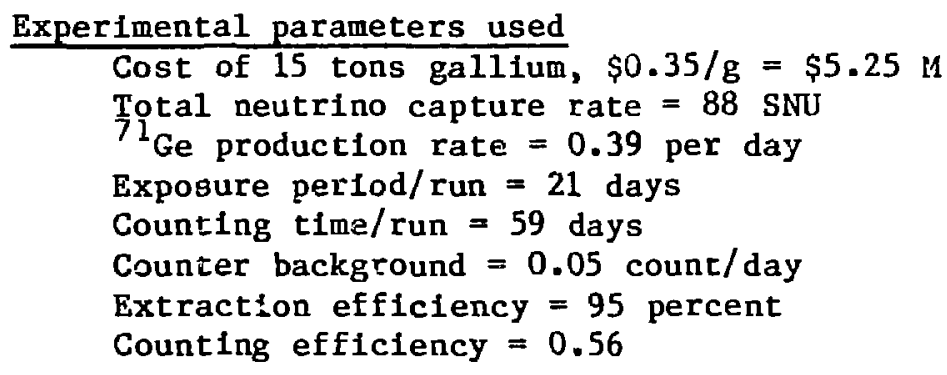

Results of the Monte Carlo Calculation

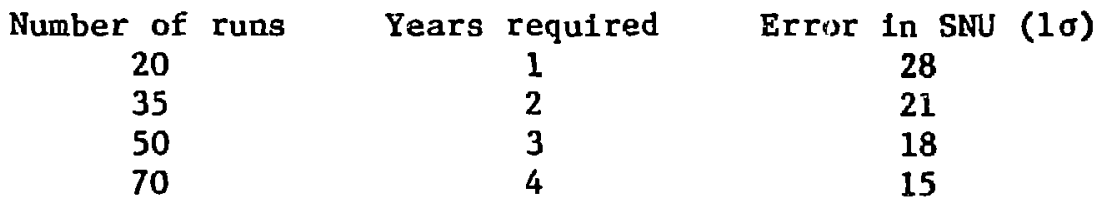

It is clear from this analysis that an experiment using 15 tons of gallium operated for three years would be capable of obtaining a significant measurement of the solar neutrino capture rate in $71 \mathrm{Ga}$. We regard 15 tons as the minimum quant Lty of gallium needed for obtaining a significant result in a reasonable time. It is interesting to note that for a given number of runs the estimated error in SNU's is approximately incependent of the neutrino capture rate. For example, if only the PPI chain is operating in the sun then the only source of neutrinos would be 
the $\mathrm{H}-\mathrm{H}$ reaction. The neutrino capture rate anticipated for ${ }^{71} \mathrm{Ga}$ would be 67 SNU's and the estimated error would be 22 SNU's in three years of operation.

Bromine. The bromine detector depends upon the neutrino capture reaction $\nu+81_{\mathrm{Br}}+e^{-}+{ }^{81} \mathrm{Kr}^{*} \rightarrow{ }^{81}{ }_{\mathrm{Kr}}$ (half-life $2.1 \times 10^{5}$ years). Neutrino capture in ${ }^{81} \mathrm{Br}(49.3 \%)$ feeds primarily the $1 / 2^{-}$ $(E=190 \mathrm{keV}) 13$-second isomeric state of ${ }^{8} \mathrm{~K}_{\mathrm{Kr}}$, with a threshold of $467 \mathrm{keV}$ for neutrino capture. The electron capture decay of this state was observed by Bennett et al, 23 and the calculated neutrino capture cross section was derived froin their measurements. 24 A $5 / 2^{-}$state at $457 \mathrm{keV}$ may also contribute to the neutrino capture cross section. The properties of this state are not sufficiently well known at the present time 25 but in the near future will be evaluated by $p, n$ reaction studies.

The bromine experiment was originally suggested as a means of testing the constancy of the solar neutrino flux over the last 500,000 years by using an old underground salt deposit as the target material.26 However, the concentration of bromine is low in these deposits, and because of this fact the alpha particle background effect from $U$ and Th impurities in known salt deposits is large. 27

Recently a method of counting $500-1000$ atoms of ${ }^{81} \mathrm{Kr}$ has been developed by G. S. Hurst and his associates at Oak Ridge National Laooratory. This development makes it possible to observe the present solar neutrino flux with the ${ }^{8} \mathrm{Br}^{-8} 1_{\mathrm{Kr}}$ method by measuring the number of ${ }^{81} \mathrm{Kr}$ atoms accumulated in a tank of a bromine containing liquid over a period of a year. In a detector comparable in size to the $\mathrm{Cl}$ detector, a solar model that is consistent with the result of the $\mathrm{Cl}$ experiment predicts that approximately two atoms of ${ }^{81} \mathrm{Kr}$ will be produced per day. The ${ }^{8} I_{\mathrm{Br}}\left(v, \mathrm{e}^{-}\right)^{81} \mathrm{Kr}$ reaction is predominantly sensitive to the monoenergetic neutrinos from $\mathrm{Be}$ decay and therefore is well suited for measuring the rate of the BPII branch. Since krypton is a rare gas, the operation of the system would be identical to that of the Howestake chlorine experiment. In fact experiments have been underway for two years to measure krypton recovery from the Homestake tank of perchloroethylene. Krypton is separated from argon by a gas chromatography step in our normal operations. Krypton is more soluble than argon in organic liquids, and of course is removed more slowly, at about $40 \%$ of the argon recovery rate. Several bromine-containing compounds are available commerclally; dibromoethane, dibromomethane, and tetrabromoethane. The least expensive is dibromoethane because this compound is manufactured on a very large scale for leaded gasoline and varlous agricultural uses, but recent prohibitions based on its presumed toxicity may rule it out.

The technique for counting 500-1000 atoms of ${ }^{81} \mathrm{Kr}$ takes advantage of a resonance ianization spectroscopy (RIS) technique for lonizing krypton atoms by multiphoton absorption. 28 The identification of $81_{K r}$ is accomplished by a mass spectrometer. To increase the efficiency of the laser-ionization step a finger cooled by liqu:-1 hellum is used to concentrate and localize the 
krypton atoms. They are released from this surface suddenly by warming the surface with a laser pulse which is followed 7 us later by the RIS laser pulse. The lonized ${ }^{8}{ }_{\mathrm{Kr}}$ atoms that pass the mass filter are accelerated to implant them in a silicon target, and counted by the secondary electrons released. All these detector components are contained in a single envelope into which the krypton sample is introduced. To apply this technique to krypton gas extracted from 400,000 liters of a brominecontaining liquid it is necessary to reduce the total volume of krypton introduced by contamination from air to a very low level. This requirement is essential because of interference from ${ }^{80} \mathrm{Kr}$ and ${ }^{82} \mathrm{Kr}$ in the mass identification. In the Homestake system the total krypton introduced in the recovery processing is no more than $10^{-6} \mathrm{~cm}^{3}$ STP. Even so it will be necessary to enrich the ${ }^{8} l_{\mathrm{Kr}}$ concentration, or utilize repeated operation of the ${ }^{81} \mathrm{Kr}$ RIS counting system.

Background effects from cosmic ray muons, internal alpha emitters, and fast neutrons are estimated to be lower than for a chlorine detector. These background problems will also produce ${ }^{79} \mathrm{Kr}\left(t_{1 / 2}=35\right.$ hours $)$ as well as ${ }^{81} \mathrm{Kr}$, whereas the production of $19 \mathrm{Kr}$ by solar neutrinos would be far lower than the production of ${ }^{81} \mathrm{Kr}$. Therafore a bromfne detector has a built-in monitor for muon background, exactly analogous to that already noted for the gallium detector.

The technology for isolating and measuring ${ }^{8} 1_{\mathrm{Kr}}$ is essentially developed and a full-scale detector is now feasible. 29 a bromine detector program could be carried out in three stages:

(1) Perform background studies in which ${ }^{81} \mathrm{Kr}$ is measured using the RIS technique along with ${ }^{7}{ }_{\mathrm{Kr}}$ by radioactivity measurements.

(2) Use the Homestake chlorine detector as a full-scale feasibility test facility to set limits on ${ }^{8} \mathrm{Kr}$ counting, and develop a routine operating i-coceciure.

(3) Build the full-scale detector.

We anticipate two years of effort are required to carry out the first two steps. We have estimated the approximate costs for a bromine experiment containing 400,000 liters of dibromomethane.

$$
\begin{aligned}
& \text { Cost of dibromomethane, } \mathrm{CH}_{2} \mathrm{Br}_{2} \quad \$ 1.2 \mathrm{M} \\
& \text { Provide an underground cavity } 0.5 \\
& \text { Tank fabrication, pumps, extraction system } 0.5 \\
& \text { Total } \overline{\$ 2.2 M}
\end{aligned}
$$

Our concept is to build a new experiment rather than fill the Homestake detector with dibromomethane. This course is recommended for the following reasons:

(1) The chlorine detector is now yielding important results in our search for solar veriations and solar flare effects.

(2) The chlorine detector is the only existing reliable monitor for the integrated neutrino flux $\left(v_{e}\right)$ from a stellar collapse or other pulsed neutrino source. 
(3) When a new detector that is sensitive to some other component of the solar neutrino spectrum is operational (such as the $\mathrm{Ga}$ or $\mathrm{Br}$ detectors) the data from the chlorine experiment will be needed. This is because of the possibility that the solar neutrino output may be varying with a period of several years and it would be most desirable to have concurrent measurements of the high-energy neutrino flux with the cl detector.

One should bear in mind that a bromine experiment requires long exposure times, of the order of a year. If ten runs are considered reasonable, a period of ten years would be needed to make an accurate measurement of the ${ }^{7} \mathrm{Be}$ flux. During this long ferind the chlorine data would be lost, and the search for solar variations, solar f'are effects, and neutrinos $\left(\nu_{e}\right)$ fro:n stellar collapse would have to be abandoned.

Underground sites. The Homestake facility, built in the period 1965-1967, has developed into a center fne ynderginni science. Four experimental programs are now established and operating in our chamber: a $500 \mathrm{~m}^{2}$ scintillation spectrometer hodoscope built by the University of Pennsylvania, a ${ }^{76} \mathrm{Ge}$ double beta decay experiment developed b: the Battelle-Northwest Laboratories and the University oi South Carolina, a radiochemical experiment to measure the nuclear interactions of muons, built by the Jmithsonian Center for Astrophysics and BNL, and the Brookhaven solar neutrino experiment. These experiments occupy all the space avaflable to science in the Homestake mine. The Homestake management at the present cime is not willing to devote the manpover and holsting capacity needed to build a new room for additional experiments.

It is our present view that a new site is needed to house a gallium or bromine experiment. A group of Canadian physicists is interested in developing an underground science laboratory in the Creighton mine operated by the International Nickel Company (INCO) near Sudbury, ontario.30 This mine has an excellert hoist that reaches a depth of 7000 feet with access to wany intermediate levels. Possible deep levels that could be used for science are at 5600 and 7000 feet. The rock structure is competent, and rooms as large or larger than the Homestake room (60 ft $\times 30 \mathrm{ft} \times 32 \mathrm{ft}$ high) could be excavated. The mine management is quite receptive to the concept of developing an underground science laboratory in the Creighton mine. We believe that an unusual opportunity exists for developing a foint Canadian-U.S. program to build a new solar neutrino observatory in the INCO mine.

\section{THE SOVIET SOLAR NEUTRINO PROGRAM}

There has been a long standing interest in solar neutrino research in the Soviet Union. It is interesting to remember that both the chlorine and gallium experiments were suggested by Soviet ecientists. 31 They have follcwed the development of the chlorine experiment and have made lany valuable contributions over the course of the last twenty years. 3 In the late $1960^{\circ}$ 's a large scale program was initiated that included building a 2-million 
11ter chlorine detector, a 50-ton gallium detector, and a 460-ton scintillatiou hodoscope. To accominodate these experiments a $4-\mathrm{km}$ long horizontal adit is being excavated in Baksan Valley ${ }^{32}$ that w111 reach an underground depth approximately equal to that of the Homestake facilicy.

Their chlorine detector is designed and a half-scale version w111 be bullt on the surface as a test facility. A six-ton gallium test faciilty has been in operation for about three years. They use metallic gallium as the target material and employ a germanium extraction technique that was developed at BNL. Tuelr program was allotted 55-60 tons of gallium and they plan to begin building a full-scale experime at in 1985 upon completion of an underground room near the end of the adit. The full-siale chlorine detectur will be built in a vary large room, $20 \mathrm{~m} \times 20 \mathrm{~m} \times 150$ meters at the end of the adit. The scientists directing the solar neutrino project are excellent, and support for their program is firm. There has been a long standing cooperation and exchange of Information between BNL and the Soviet program, and occasional short term exchange visits of a few scientists.

\section{ACKNOWLEDGHENT}

Th1: research was carried out at Brookhaven National Laboratoxy under contract DE-ACO2-76CHOOO16 with the U.S. Department of Energy and supported by Its Office of High Energy and Nuclear Physics.

\section{REFERENCES}

1. W. Haxton, report presented to Conference on Intersection between Particle and Nuclear Physics.

2. J. N. Bahcall, W. F. Huebner, S. H. Lubow, P. D. Parker, and R. K. Ulrich, Rev. Mod. Phys. 54, 767 (1982) and references therein.

3. J. N. Bahcail and R. Davis, Jr., Essays in Nuclear Astrophysics, P. 243, C. A. Barnes, D. D. Clayton, and D. Schramm.

4. A Wolfendale, E. C. M. Young, and R. Davis, Jr., Nature Physical Sclences 238, 130 (1972).

5. R. Davis, Jr., B. T. Cleveland, J. C. Evans, ani J. K. Rowley, Bul1. Am. Phys. Soc. 29 (No. 4), 731 (19u4); G. A. Basilevskaya, S. I. Nikolski1, Yu. I. Stozhkov, T. N. Charakhchyan, A. M.-A. Mukhamedzhanov, 18th Intern. Cosmic Ray Conf. Sp-6-4 (1983), and preprint submitted to J. Nucl. Phys. (USSR) Dec. 1983; A. Subramanian and S. Lal; Current Science 52, 342 (1983) and preprint TIFR-BC-83-12.

6. J. N. Bahcall, W. F. Heubner, S. H. Lebow, P. D. Parker, and R. K. Ulrich, Rev. Mod. Phys. 54, 767 (1982); B. Filippone and D. Schramm, Astrophys. J. $\overline{253}, 393$ (1982); W. A. Fowler, AIP Conf. Pro:. No. 96, p. $80 \overline{(1982) .}$ 
7. J. L. Osborne, C. A. Barnes, R. W. Kavanagh, R. M. Kremer, G. J. Mathews, J. L. Zyskind, P. D. Parker, and A. J. Howard, Phys. Rev. Lett. 48, 1664 (1982); H. Krawinkel, H. W. Becker, L. Bachmann, J. Gorres, K. U. Kettner, W. E. Kieser, R. Sanco, P. Schmalbrock, H. P. Trautvetter, A. Vlieks, C. Rolfs, J. W. Hammer, R. E. Azuma, and W. S. Rodney, Z. Phys. A304, 307 (1982); R. G. H. Robertson, P. Dyer, J. T. Bowles, R. E. Brown, N. Jarmie, C. J. Maggiore, and S. M. Austin, Phys. Rev. C27, 11 (1983); T. K. Alexander, G. C. Ball, W. N. Lennard, H. Gelssel, and H.-B. Mak, Preprint, Chalk River Nuclear Laboratories.

8. B. W. Filippone, A. J. Elwyn, C. N. Davids, and D. D. Koetke, Phys. Rev. C28, 2222 (1983).

9. R. T. Rood, Proc. Infornal Conference on the Status and Future of Solar Neutrino Research, G. Friedlander, Editor, BNL 50879, Vol. 1, p. 175 (1978); R. K. Ulrich, E. J. Rhodes, S. Tomezyk, P. J. Dumont, W. M. Brunish, AIP Conf. Proc. No. 96, p. $6 f$ (1982).

10. S. M. Bilenkii and B. M. Pontecorvo, Soviet Phys. Usp. 20, 776 (1977).

11. Lo Wolfenstein, Phiys. Rev. D17, 2369 (1978).

12. V. Barger, K. Whisnant, and R. J. N. Phillips, Phys. Rev. D24, 538 (1981).

13. Proc. Informal Conference on the Status and Future of Solar Neutrino Research, G. Friedlander, Editor, BNL 50879.

14. M. Deutseh, this conference; R. S. Raghavan, Phys. Rev. Lett. 37, 259 (1976); L. Pfeiffer, A. P. Mills, Jr., R. S. Raghavan, and E. A. Charidross, Phys. Rev. Lett. 41, 63

15. M. S. Freedman, C. M. Stevens, E. P. Horwitz, L. H. Fuchs, J. S. Lerner, L. S. Goodman, W. J. Childs, and J. Hessler, Science 193, 1117 (1976); M. Freedman, Bull. Inst. Chem. Res. 57, 117 (1979), Kyoto Univ.; for a background analysis see ref. 24.

16. J. K. Rowley, Proc. Informal Conf. on the Status and Future of Solar Neutrino Research, G. Friedlander, Editor, BNL 50879.

17. H. Chen, P. J. Doe, and H-J. Mahler, AIP Conf. Proc. No. 96, p. 182 (1982).

18. A. Mann, Report at this conference.

19. C. Goodman, Comments Nucl. Part. Phys. 10, 117 (1981).

20. W. Hampel, AIP Conf. Proc. No. 96, p. $8 \overline{8}$ (1982).

21. J. N. Bahca11, B. T. Cleveland, R. Davis, Jr., I. Dostrovsky, J. C. Evans, Jr., W. Frat1, G. Friedlander, K. Iaande, J. K. Rowley, R. W. Stoenner, and J. Weneser, Phys. Rev. Lett. 40 , 1351. (1978).

22. W. Hampel, private report to gallium collaboration Jan. 198 .

23. C. L. Bennett, M. M. Lowry, R. A. Naumann, F. Loeser, and W. H. Moore, Phys. Rev. C 22, 2245 (1980).

24. J. N. Bahcal1, Phys. Rev. C 24, 2216 (1981); W. C. Haxton, Nucl. Phys. A367, 517 (1981).

25. K. F. Liu and F. Gabbard, Phys. Rev. C 27, 93 (1983). 
26. R. D. Scott, Nature 264, 729 (1976), Proc. Informal Conf . on the Status and Future of Solar Neutrino Research, G. Friedlander, Editor, BNL Report 50879, p. 293 and T. Kirsten, 1bid., p. 305.

27. J. K. Rowley, B. T* Cleveland, R. Davis, Jr., W. Hampe1, and T. Kirsten, The Ancient Sun, R. O. Pepin, J. A. Eddy, and R. B. Merri11, Editors, p. 45.

28. C. H. Chen, S. D. Kramer, S. L. Allman, and G. S. Hurst, Appl. Phys. Lett. 44, 640 (1984); C. H. Cher, Proc. 2nd Symp. on Resonance Ionization Spectrcscopy and its Applications (Adain Hilger Ltd., 1984); S. D. Kramer, Ibid.

29. G. S. Hurst, C. H. Chen, S. D. Kramer, B. T. Clevelani, R. Davis, Jr., J. K. Rowley, F. Gabbard, and F. J. Schima, submicted for publication, June 1984.

30. W. F. Davidson, P. Depommier, G. T. Ewan, and H.-B. Mak, report in Proc. Intern. Conf. on Baryon Non-Conservation (ICOBAN) Park City, Utah, Jan. 4-7, 1984.

31. Chlorine: B. Ponterorvo, P.D.-205, Chalk River, Ontario, 20 Nov. 1946; Gallium: V. A. Kuzmin, Sov. Phys. JETR 22, 1051 (1966).

32. A. A. Pomanski1, Soviet Atomic Energy 44, 433 (1978).

\section{DISCLAIMER}

This report was prepared as an account of work sponsored by an agency of the United States Gvernment. Neither the United States Government nor any agency thereof, nor any of their employees, makes any warranty, express or implied, or as'"mes any legal liability or responsibility for the accuracy, complcteness, ir usefulness of any infornution, apparatus, product, or process disclosed, or represents that it; use would not infringe privately owned rights. Reference herein to any specific commercial product, process, or service by trade name, trademark, manufacturer, or otherwise does not necessarily constitute or imply its endorsement, recommendation, or favoring by the United States Government or any agency thereof. The views and opinions of authors expressed berein do not necessarily state or reflect thnse of the United States Government or any agency thereof. 